\title{
PRODUÇÃO DE BIOENERGIA, SEGURANÇA AMBIENTAL E DESENVOLVIMENTO ECONÔMICO'
}

\author{
Pedro Luiz Teixeira de Camargo ${ }^{2}$ \\ Paulo Pereira Martins Junior ${ }^{3}$
}

\begin{abstract}
RESUMO
O presente artigo propõe debater acerca da relação entre segurança ambiental, conservação dos biomas, produção de material para bioenergia e gestão estruturada de uso da terra em propriedades rurais para conservação dos solos e da bacia hidrográfica. Para isso, propõe-se o uso da metodologia denominada Corredores Florestais Ecológicos Econômicos (CFEE). Para garantir seu sucesso metodológico, é preciso que sejam, de fato, corredores ideais capazes de resgatar espaços ecológicos econômicos florestais. Assim, antes de sua construção é ideal que se obedeçam aos diversos postulados pedológicos, geomorfológicos, agrícolas e biológicos, denominados condições ideais e resumidos através dos Desenhos de Uso Optimal do Território (DUOT). Somente pós obedecer estas condições, é possível de fato se construir tais CFEE, buscando seu máximo sucesso, que pode ser verificado através da replicação experimental proposta, realizada por Camargo (2018), confirmando que os pressupostos teóricos aqui apresentados mostram resultados de fato positivos. Como conclusão, pode-se afirmar que os modelos aqui discutidos integram uma visão de viabilidade ecológica e econômica entre plantios florestais ecológicos e econômicos, com conservação do bioma e da circulação hídrica, com o uso de agricultura intensiva para a produção de biomassa, madeiras de lei, frutos e fármacos com vista a eco sustentabilidade das bacias hidrográficas.
\end{abstract}

Palavras-chave: Corredores Florestais Ecológicos Econômicos (CFEE). Desenhos de Uso Optimal do Território (DUOT). Ordenamento Territorial (OT).

\section{BIOENERGY PRODUCTION, ENVIRONMENTAL SAFETY AND ECONOMIC DEVELOPMENTEM}

\begin{abstract}
This article proposes to debate about the relationship between environmental security, conservation of biomes, production of material for bioenergy and structured management of land use in rural properties for soil and watershed conservation. For this, it is proposed to use the methodology called Ecological Economic Forest Corridors (CFEE). To guarantee its methodological success, it is necessary that they are, in fact, ideal corridors capable of rescuing forest economical ecological spaces. Thus, before its construction, it is ideal to obey the various pedological, geomorphological, agricultural and biological postulates, called ideal conditions

\footnotetext{
${ }^{1}$ Como citar este artigo: CAMARGO, P. L. T.; MARTINS JUNIOR, P. P. Produção de bioenergia, segurança ambiental e desenvolvimento econômico. ForScience, Formiga, v. 8, n. 2, e00718, jul./dez. 2020.

${ }^{2}$ Autor para correspondência: Pedro Luiz Teixeira Camargo, e-mail: pedro.camargo@ifmg.edu.br

${ }^{3}$ Autor para correspondência: Paulo Pereira Martins Junior, e-mail: paulomartins@epamig.br
} 
and summarized through the Drawings of Optimal Use of the Territory (DUOT). Only after obeying these conditions, it is possible to actually build such CFEE, seeking its maximum success, which can be verified through the experimental replication proposed by Camargo (2018), confirming that the theoretical assumptions presented here show really positive results. As a conclusion, it can be said that the models discussed here integrate a vision of ecological and economic feasibility between ecological and economic forest plantations, with conservation of the biome and water circulation, with the use of intensive agriculture for the production of biomass, hardwood, fruits and drugs with a view to the eco-sustainability of watersheds.

Keywords: Ecological Economic Forest Corridors (CFEE). Drawings of Optimal Territory Use (DUOT). Territorial Planning (OT).

\section{INTRODUÇÃO}

Este estudo é derivado de pesquisas conceituais ${ }^{4}$ dentro do conceito de Ordenamento Territorial (OT), área que, muitas vezes, trabalha com a lógica do sensoriamento remoto, em que o uso da radiação eletromagnética pode ser utilizado para a aquisição de informações referentes a um determinado local ou objeto (ROSA, 2007). Desta forma, desde 1992 vem se desenvolvendo pesquisas acerca desta temática de modo contínuo; e a partir de 2013, atua-se no Norte de Minas Gerais com as seguintes atividades: renovação da fábrica de derivados florestais de frutos do bioma Cerrado derivados do extrativismo, duas teses no munícipio de São Francisco intituladas "Soluções biogeográficas de geoconservação com ênfase nas relações entre solo, água e planta na bacia do rio Pardo e suas adjacências" (CAMARGO, 2018) e "Implicações Geoambientais para o Desenvolvimento da Teoria do Sistema Computacional de Suporte à Decisão para Gestão do Território e da Erosão dos Solos” (TEIXEIRA, 2018).

Segurança em geral e ambiental, em específico, são a rigor idênticas em virtude de existir, ao mesmo tempo, a interação do ambiente de produção industrial com os ambientes naturais, definindo-se este como um ambiente que não oferece risco para a continuação da vida humana (KLUBNIKIN; CAUSEY 2002).

Curiosamente, este conceito de segurança ambiental encontrou muito mais resistência científica de aceitação que o seu termo originário, o desenvolvimento sustentável (ELLIOT, 1998), mostrando como, ainda hoje, sua definição é ainda complexa. Assim, lidar com segurança implica em trabalhar com a produção de modo articulado, inteligente, criativo e inovador, sempre com o foco na qualidade, minimizando-se ao máximo o consumo energético com mínima produção de resíduos não recicláveis e, consequente, desenvolvimento humano crescente. Em resumo, é preciso o que Holling (1996) define como resiliência.

\footnotetext{
${ }^{4}$ As pesquisas teóricas aqui descritas têm sido desenvolvidas pelo grupo de Pesquisas em Geociências Agrárias e Ambientais, formada por pesquisadores de diversas Instituições nos últimos 20 anos.
} 
O conceito integrado, portanto, acerca de uma segurança resiliente pode fazer com que este se torne 'o conceito categórico' para uma política cada vez mais eficiente em produzir por quantidade, qualidade, melhor logística e menor consumo de energia, ou seja, a resiliência ambiental é a chave para a segurança ambiental (ADGER, 2000), questão central para o processo de desenvolvimento bioenergético do Brasil, com efeitos no domínio geopolítico da soberania nacional.

Assim, a soberania nacional implica em articular a eficiência produtiva (VICENTE, 2002), em territórios bem gerenciados geodinamicamente, com boa metaestabilidade e que envolva os seguintes macro aspectos: 1) Conservação rigorosa da circulação hídrica em todos os níveis superficiais das bacias hidrográficas; 2) Conservação das zonas de recarga e das áreas precisas de recarga dos aquíferos subterrâneos; 3) Prevenção e correção de todos os processos de erosão dentro das bacias; e 4) Revegetação das áreas desmatadas com o uso do conceito de corredores florestais ecológicos e econômicos (CFEE) como mostra a FIG. 1.

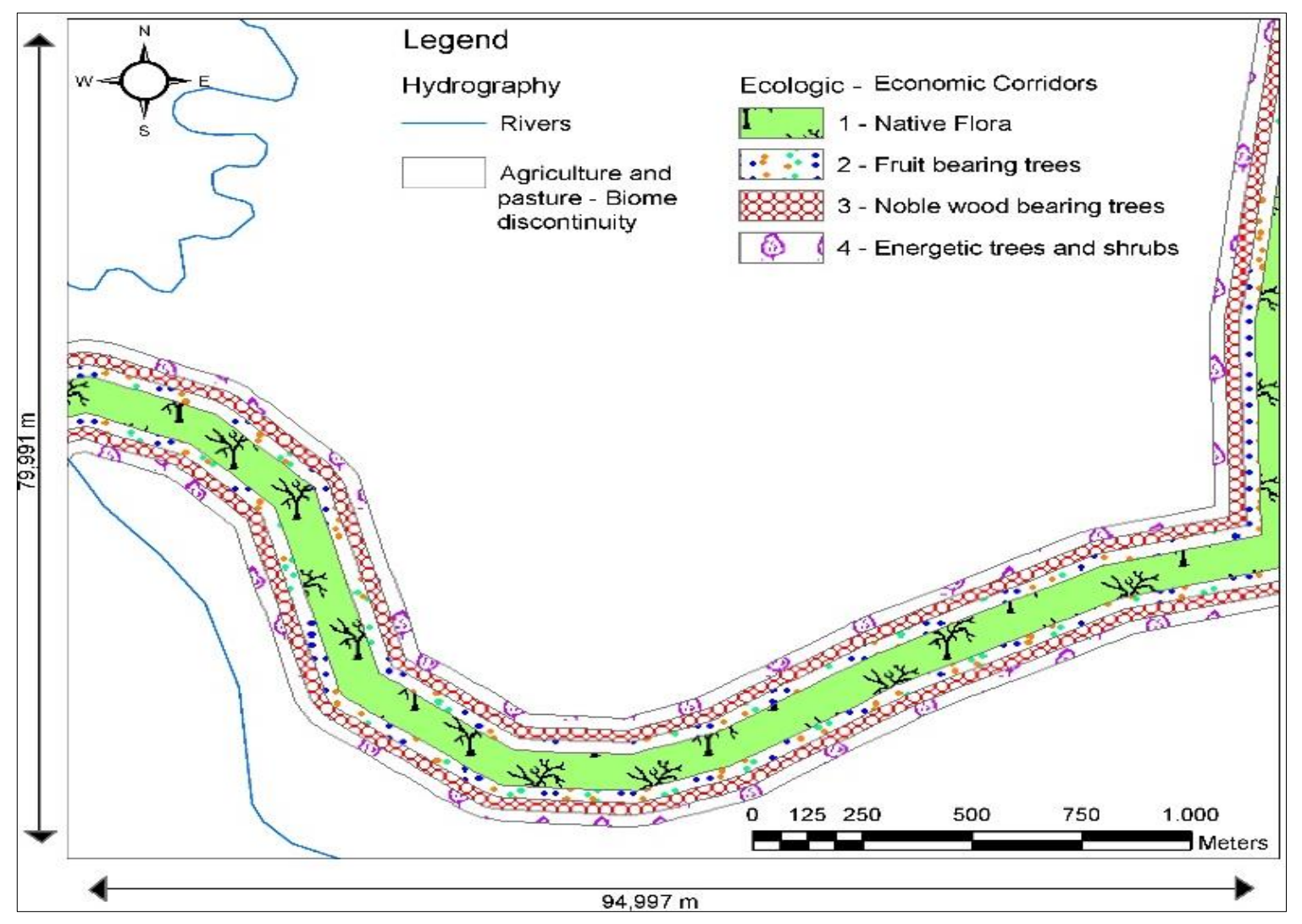

Figura 1 - Geometria dos Corredores Florestais Ecológicos e Econômicos Fonte: Martins Júnior (1998).

Esses quatro aspectos são cruciais tanto quando se pensa em uma política nacional de segurança ambiental como para a produção de biomassa voltada à produção energética. Em 2003, a biomassa vegetal chegou a ser responsável por aproximadamente $20 \%$ da geração de 
energia na nação brasileira (BRASIL, 2003). Portanto, a conservação da quantidade e qualidade da água dialogam diretamente com uma política de alta tecnologia agrícola que objetive maior produtividade, com menor uso de água e biocidas. Acerca desses herbicidas, segundo Bombardi (2017), o Brasil é o país que mais consome agrotóxicos do planeta, algo preocupante que mostra como propostas capazes de apresentar tecnologias limpas não só é uma necessidade histórica, mas uma solução ecológica.

Para isso, a combinação da produção agrícola intensiva para a fabricação de biomassa através de técnicas de silvicultura (REZENDE; PEREIRA; OLIVEIRA, 1983; BERGER, 2000), bem como soluções agroflorestais ligadas à densidade de corredores e maciços ecológicos econômicos (SHIMOYAMA; BARRICHELO, 1989) abrem oportunidades de produções mais complexas e com maiores possibilidade de expansão industrial quando focadas em produzir frutos, sucos, doces e madeira de lei para a indústria moveleira - Astronium fraxinifolium, (ALVES et al., 20005 apud LORENZI, 1997), para a indústria civil - Eucalyptus saligna- (BERGER, 2000), produção de produtos farmacopeicos derivados, como óleos essenciais, princípios ativos para fármacos e cosméticos, como a Mama Cadela - Brosimum gaudichaudii - (LORENZI, 1997) e, ainda a indústria carvoeira vegetal para suporte da indústria siderúrgicaAroeira - Schinus terebinthifolius - (LORENZI, 1997).

Assim, integrando-se mais de 25 anos de pesquisas e de desenvolvimentos metodológicos e tecnológicos de OT é que esse estudo objetiva realizar uma necessária revisão bibliográfica acerca da segurança ambiental, da conservação dos biomas, da produção de material para bioenergia e da gestão estruturada de uso da terra em propriedades rurais para conservação dos solos e das bacias hidrográficas.

\section{METODOLOGIA}

Uma vez que este é um artigo teórico, de revisão bibliográfica e metodológica para o uso de OT relacionado diferentes técnicas de gestão ambiental, a metodologia de pesquisa se deu com base em levantamento bibliográfico acerca do tema, seu respectivo fichamento, observações de trabalhos anteriores e, consequente, obtenção de resultados acerca da temática apresentada.

\footnotetext{
5 ALVES, Tânia Maria de Almeida; SILVA, Andréia Fonseca; BRANDÃO, Mitzi; GRANDI, Telma Sueli Mesquita; SMÂNIA, Elza de Fátima A; SMÂNIA JÚNIOR, Artur; ZANI, Carlos Leomar. Biological screening of brazilian medicinal plants. Memórias do Instituto Oswaldo Cruz, Rio de Janeiro, v. 96, n. 3, p. 367-373, 2000.
} 


\section{DESENVOLVIMENTO}

\subsection{Corredores Florestais Ecológicos Econômicos (CFEE)}

Conceberam-se os CFEEs para se responder a variadas situações que necessitem de soluções de mitigação viáveis. Assim, baseado em Oliveira (2004), parte-se dos seguintes princípios:

1) Grandes extensões de terras têm sido desmatadas tendo como consequência a extinção de espécies e a interrupção da migração de espécimes de animais em época de reprodução, isso afeta a vegetação em seu processo reprodutivo, destruindo-se diversos tipos arbóreos importantes e rentáveis para a industrialização florestal, ameaçando-se de modo sistemático a circulação hídrica. Por óbvio, a disponibilidade de água tende a cair e, por conseguinte, o seu consumo, gerando-se um quadro de degradação ambiental ao longo do tempo, ainda que essa degradação não se manifeste sempre rapidamente. Como colocado por Ab'Saber (2003), a falta de vegetação original atrapalha a infiltração hídrica no solo, diminuindo assim a sua capacidade de absorção e retenção.

2) Toda solução de mitigação deve ser rentável em um dado tempo de retorno, mensurável.

3) A rentabilidade deve ser apropriada pelos proprietários rurais agricultores e criadores.

4) As soluções a serem obtidas devem ser diversas no contex to de utilização de plantas arbóreas, principalmente, com variadas aplicações industriais.

5) Todo este cenário sendo desenvolvido, favorecerá a formação profissional de jovens, podendo gerar empregos para novas indústrias de beneficiamento no entorno das áreas que necessitem de resgate florestal ambiental.

6) Geração de empregos para várias categorias de engenharias.

7) Aumento da arrecadação de impostos devido ao crescimento industrial de bases agroflorestais.

8) Finalmente pode-se tentar estabelecer a segurança hídrica e a qualidade dos solos em questão.

\subsection{Metodologia dos Corredores Ideais}

Essa metodologia pode ser pensada como formas de religar maciços florestais remanescente, bem como campos e florestas de galeria também. Assim, os corredores são 
apresentados em modelo ideal, segundo Martins Júnior (2014), Martins Júnior e Vasconcelos (2014), Martins Júnior et al. (1998) e Martins Júnior et al. (2010), da seguinte forma:

1) São cinco faixas de tipos de plantas, uma central e duas laterais em cada lado.

2) No centro, a faixa deve ser composta com plantas exclusivamente nativas do bioma, especificamente do ecossistema ou ainda com feições anteriormente existentes, conforme as possibilidades possíveis.

3) A primeira faixa lateral junto à faixa central será composta de plantas que não serão abatidas, mas que se possa extrair frutos, sendo as mais indicadas para o cerrado, de acordo com Camargo (2018), a goiaba (P. guajava), a manga ( $M$. indica) e o jatobá ( $H$. courbaril).

4) A faixa seguinte poderá (ou deverá ser) de árvores de interesse industrial para a indústria moveleira e civil, o que vem a ser as madeiras nobres. Segundo Camargo (2018), as mais indicadas são a aroeira (S. terebinthifolius) e o pau jeú (Triplaris sp.).

5) Perfazem esses corredores fortes bases para sustentar amplos programas de industrialização rural. Inclui-se também madeiras para móveis, carvão vegetal e briquetes, bem como produtos para a indústrias de material de limpeza como apresentado por Camargo et al. (2017).

\subsection{Resgate de Espaços Ecológicos Econômicos Florestais}

Das situações reais às soluções possíveis, deve-se passar por uma série de técnicas de plantios com o enfoque voltado ao conceito de florestas ecológicas e econômicas como soluções precursoras das proposições ecológico-econômicas integradas. Essas técnicas visam apresentar múltiplas soluções para as situações diversas que, necessariamente, poderão se apresentar nos territórios com demanda reconhecíveis de soluções de replantio, seja para a conservação do bioma, seja para a construção de novos corredores (MARTINS JÚNIOR et al., 2008; MARTINS JÚNIOR et al., 2010). As QUAD. 1 e 2 apresentam, em síntese, essas possíveis situações e seus respectivos desafios. 


\begin{tabular}{|l|l|l|}
\hline \multicolumn{1}{|c|}{ SITUAÇÕES REAIS } & \multicolumn{1}{|c|}{ SOLUÇÕES POSSÍVEIS } & \multicolumn{1}{|c|}{ DESAFIOS GEOAMBIENTAIS } \\
\hline $\begin{array}{l}\text { Desmate intensivo sobre grandes } \\
\text { extensões }\end{array}$ & $\begin{array}{l}\text { Replantio com florestas } \\
\text { ecológicas e ecológico- } \\
\text { econômicas }\end{array}$ & $\begin{array}{l}\text { Integrar soluções ecológico- } \\
\text { econômicas aos projetos agrícolas } \\
\text { atuais ou recuperar pastos } \\
\text { improdutivos }\end{array}$ \\
\hline $\begin{array}{l}\text { Efeitos de borda em maciços e } \\
\text { corredores remanescentes }\end{array}$ & $\begin{array}{l}\text { Replantio nas áreas fragilizadas } \\
\text { dos maciços }\end{array}$ & $\begin{array}{l}\text { Usar espécies econômicas ou } \\
\text { protetoras para o entorno dos } \\
\text { maciços garantindo correta relação } \\
\text { com o solo }\end{array}$ \\
\hline $\begin{array}{l}\text { Descontinuidade floral total sobre } \\
\text { grandes superfícies }\end{array}$ & $\begin{array}{l}\text { Reconstrução de corredores } \\
\text { estratégicos com delineamentos } \\
\text { direcionais }\end{array}$ & $\begin{array}{l}\text { Seleção de áreas sensíveis prioritárias } \\
\text { geoambientais e de relações espaço } \\
\text { topológicas adequadas para as } \\
\text { espécies animais da região }\end{array}$ \\
\hline $\begin{array}{l}\text { Corredores mal construídos e com } \\
\text { efeitos de borda }\end{array}$ & $\begin{array}{l}\text { Plantio de segurança com } \\
\text { soluções econômicas }\end{array}$ & $\begin{array}{l}\text { Reconstrução geoambiental dos } \\
\text { corredores com espécies ecológicas e } \\
\text { econômicas }\end{array}$ \\
\hline $\begin{array}{l}\text { Matas remanescentes ausentes ou } \\
\text { insignificantes }\end{array}$ & Reconstrução de maciços & $\begin{array}{l}\text { Escolha de áreas geoambientais } \\
\text { adequadas para a reconstrução de } \\
\text { maciços }\end{array}$ \\
\hline $\begin{array}{l}\text { Matas remanescentes presentes e muito } \\
\text { isoladas }\end{array}$ & Ampla instalação de corredores \\
\hline $\begin{array}{l}\text { Matas remanescentes bem distribuídas, } \\
\text { mas com grandes distâncias para } \\
\text { algumas espécies animais originárias }\end{array}$ & $\begin{array}{l}\text { Corredores mais curtos e em } \\
\text { número maior para interligar os } \\
\text { maciços } \\
\text { corredores com bases geoambientais }\end{array}$ & $\begin{array}{l}\text { Articulação dos corredores com os } \\
\text { projetos agrícolas existentes }\end{array}$ \\
\hline $\begin{array}{l}\text { Areas a serem permitidas para desmate } \\
\text { expansão agrícola }\end{array}$ & $\begin{array}{l}\text { Ressalvar as condições de } \\
\text { conservação do local }\end{array}$ \\
\hline
\end{tabular}

Quadro 1 - Relação entre situações reais, soluções e desafios geoambientais

Fonte: Adaptado de Martins Júnior et al. (2008), NT inédita referente ao Projeto ACEE (2005-2008).

(Continua)

\begin{tabular}{|c|c|c|c|c|c|}
\hline $\begin{array}{c}\text { OBJETIVOS X } \\
\text { SOLUÇÕES DE } \\
\text { ORDENAMENTO } \\
\text { DO TERRITÓRIO }\end{array}$ & $\begin{array}{c}1 \\
\text { USO DE } \\
\text { TERRAS } \\
\text { AGRÍCOLAS E } \\
\text { AGRICULTURÁ } \\
\text { VEIS } \\
\end{array}$ & $\begin{array}{c}2 \\
\text { CONTINUIDA } \\
\text { DE FLORAL }\end{array}$ & $\begin{array}{c}\text { 3 } \\
\text { SUSTENTAÇÃO } \\
\text { DA } \\
\text { INFRAESTRUTU } \\
\text { RA }\end{array}$ & $\begin{array}{c}4 \\
\text { VIABILIDA } \\
\text { DE DO } \\
\text { PLANTIO }\end{array}$ & $\begin{array}{c}5 \\
\text { ENG }^{\mathrm{A}} \text {. } \\
\text { FLORESTAL + } \\
\text { ECOLOGIA + } \\
\text { PRODUTIVIDAD } \\
\text { E } \\
\end{array}$ \\
\hline $\begin{array}{l}\text { Solução ecológico- } \\
\text { econômica }\end{array}$ & $\begin{array}{l}\text { permite } \\
\text { conservação da } \\
\text { terra e da água }\end{array}$ & $\begin{array}{l}\text { viabilizar } \\
\text { soluções contra } \\
\text { a resistência } \\
\text { cultural }\end{array}$ & $\begin{array}{l}\text { soluções que } \\
\text { integram } \\
\text { geociências + eng. } \\
\text { florestal }\end{array}$ & $\begin{array}{l}\text { oferece o } \\
\text { modo mais } \\
\text { simples, } \\
\text { eficiente e } \\
\text { menos } \\
\text { oneroso }\end{array}$ & $\begin{array}{l}\text { apoia a eng }{ }^{\mathrm{a}} \text {. } \\
\text { florestal e a } \\
\text { produtividade } \\
\text { efetiva }\end{array}$ \\
\hline $\begin{array}{l}\text { Solução } \\
\text { conservacionista }\end{array}$ & $\begin{array}{l}\text { insere uma } \\
\text { cultura ecológica } \\
\text { na prática } \\
\text { produtiva }\end{array}$ & $\begin{array}{l}\text { a própria } \\
\text { solução } \\
\text { conservacionist } \\
\text { a se baseia na } \\
\text { continuidade }\end{array}$ & $\begin{array}{l}\text { integra infra- } \\
\text { estrutura com } \\
\text { proteção floral }\end{array}$ & $\begin{array}{l}\text { só é viável e } \\
\text { efetiva se } \\
\text { encontrada a } \\
\text { viabilidade } \\
\text { de plantio e } \\
\text { crescimento }\end{array}$ & $\begin{array}{l}\text { integra tecnologia } \\
\text { florestal com } \\
\text { conservação e } \\
\text { produtividade } \\
\text { rentável }\end{array}$ \\
\hline Corredores & $\begin{array}{l}\text { serve para } \\
\text { consórcios agro- } \\
\text { silvi-pastoris }\end{array}$ & método ideal & $\begin{array}{l}\text { protege áreas } \\
\text { sensíveis }\end{array}$ & $\begin{array}{l}\text { substitui } \\
\text { agricultura, } \\
\text { permite } \\
\text { reconquista } \\
\text { de terras } \\
\text { degradadas }\end{array}$ & $\begin{array}{l}\text { podem portar } \\
\text { qualidades de } \\
\text { florestas } \\
\text { econômicas com } \\
\text { funções } \\
\text { ecológicas }\end{array}$ \\
\hline $\begin{array}{l}\text { Estrutura de } \\
\text { corredores }\end{array}$ & $\begin{array}{l}\text { compõe matas } \\
\text { naturais e } \\
\text { plantadas de } \\
\text { modo articulado }\end{array}$ & $\begin{array}{l}\text { a continuidade } \\
\text { é protegida } \\
\text { pela floresta } \\
\text { econômica e/ou } \\
\text { natural }\end{array}$ & $\begin{array}{l}\text { articula florestas } \\
\text { nativas com } \\
\text { soluções de } \\
\text { conservação }\end{array}$ & $\begin{array}{l}\text { envolve } \\
\text { técnicas de } \\
\text { plantio para } \\
\text { nativas, } \\
\text { pioneiras e }\end{array}$ & $\begin{array}{l}\text { produtividade nas } \\
\text { faixas nativas, ou } \\
\text { não, e nas faixas } \\
\text { de exóticas }\end{array}$ \\
\hline
\end{tabular}


CAMARGO, P. L. T.; MARTINS JUNIOR, P. P. Produção de bioenergia, segurança ambiental e desenvolvimento econômico

\begin{tabular}{|c|c|c|c|c|c|}
\hline & & & & $\begin{array}{l}\text { econômicas } \\
\text { articuladas }\end{array}$ & \\
\hline $\begin{array}{l}\text { Conservação } \\
\text { florestal }\end{array}$ & $\begin{array}{l}\text { em áreas nativas } \\
\text { e com interesses } \\
\text { econômicos }\end{array}$ & $\begin{array}{l}\text { continuidade } \\
\text { florestal }\end{array}$ & $\begin{array}{l}\text { sustenta a } \\
\text { infraestrutura } \\
\text { natural }\end{array}$ & $\begin{array}{l}\text { responde à } \\
\text { agregação de } \\
\text { espécimes }\end{array}$ & $\begin{array}{l}\text { maior o viés } \\
\text { preservado e } \\
\text { menor o viés } \\
\text { econômico }\end{array}$ \\
\hline $\begin{array}{l}\text { Conservação das } \\
\text { relações } \\
\text { plantas/solos/água }\end{array}$ & $\begin{array}{l}\text { manutenção } \\
\text { dessas relações } \\
\text { no processo } \\
\text { agrícola }\end{array}$ & $\begin{array}{l}\text { intercalação } \\
\text { agricultura e } \\
\text { florestas }\end{array}$ & $\begin{array}{l}\text { relações necessárias } \\
\text { que dependem da } \\
\text { infraestrutura }\end{array}$ & $\begin{array}{l}\text { aperfeiçoam } \\
\text { ento das } \\
\text { relações pela } \\
\text { conjugação } \\
\text { de insumos } \\
\text { de digestão } \\
\text { anaeróbica e } \\
\text { aeróbica }\end{array}$ & $\begin{array}{l}\text { necessita de } \\
\text { soluções integrais } \\
\text { para } \\
\text { florestamento }\end{array}$ \\
\hline $\begin{array}{l}\text { Integração da } \\
\text { fitossociologia em } \\
\text { reflorestamentos }\end{array}$ & $\begin{array}{l}\text { fitossociologia } \\
\text { de plantas } \\
\text { domesticadas }\end{array}$ & $\begin{array}{l}\text { fitossociologia } \\
\text { aplicada ao } \\
\text { florestamento e } \\
\text { reflorestamento }\end{array}$ & $\begin{array}{l}\text { viabilização da } \\
\text { floresta replantada } \\
\text { com nativas e } \\
\text { exóticas }\end{array}$ & $\begin{array}{l}\text { viabilidade } \\
\text { de sucesso } \\
\text { no plantio }\end{array}$ & $\begin{array}{l}\text { garantia de } \\
\text { crescimento e } \\
\text { produtividade }\end{array}$ \\
\hline Permacultura & $\begin{array}{l}\text { resgata áreas } \\
\text { agrícolas; } \\
\text { aproveita melhor } \\
\text { áreas nobres }\end{array}$ & $\begin{array}{l}\text { integra a } \\
\text { continuidade } \\
\text { no projeto } \\
\text { econômico }\end{array}$ & $\begin{array}{l}\text { conserva solos e } \\
\text { conserva a } \\
\text { hidrodinâmica }\end{array}$ & $\begin{array}{l}\text { método } \\
\text { excelente } \\
\text { para } \\
\text { viabilizar } \\
\text { integração } \\
\text { agroflorestal }\end{array}$ & $\begin{array}{l}\text { pela agricultura } \\
\text { viabiliza a espera } \\
\text { da produção } \\
\text { florestal }\end{array}$ \\
\hline Inclusão social & $\begin{array}{l}\text { exige melhor } \\
\text { formação do } \\
\text { agricultor }\end{array}$ & $\begin{array}{l}\text { gera trabalho } \\
\text { ao silvicultor }\end{array}$ & $\begin{array}{l}\text { oportunidade de } \\
\text { trabalho com } \\
\text { engenharia agrícola } \\
\text { e geotecnia }\end{array}$ & $\begin{array}{l}\text { desenvolve } \\
\text { especialistas } \\
\text { em plantio }\end{array}$ & $\begin{array}{l}\text { agrega } \\
\text { especialistas, } \\
\text { fechando a cadeia } \\
\text { profissional }\end{array}$ \\
\hline
\end{tabular}

Quadro 2 - Objetivos dos plantios e condições gerais de uso da terra para corredores ecológicos econômicos e produção energética de biomassa, com os significados cruzados dos objetivos atendidos por métodos selecionados para o ordenamento territorial Fonte: Baseado em Martins Júnior et al., 2006.

Quanto aos corredores, deve-se ter como critério lógico o fato de que o modelo proposto é um modelo ideal sujeito a modificações cabíveis de acordo com restrições das mais diversas ordens:

1) Não ocupar eventualmente a maior parte da terra agricultável de algum proprietário;

2) O proprietário já deve ter atendido às exigências florestais legais obrigatórias;

3) O campo da propriedade, mesmo o já especializado em agricultura de herbáceas, não possuir espécies arbóreas (ou apresentar poucas);

4) Haver dificuldades de plantios graças às condições do substrato;

5) Ter obras de engenharia na direção ideal pressuposta para um corredor;

6) Algum proprietário oferecer resistência à largura do empreendimento ou preferir atender a parte das faixas de plantio do modelo padrão; e

7) Vir a consumir importantes áreas de agricultura intensiva ou de pastagens produtivas. 


\subsection{Condições dos Desenhos de Uso Optimal do Território [DUOT] como Mapas do Futuro}

Os métodos progressivamente desenvolvidos para gestão territorial, com foco nos zoneamentos ambientais, econômicos, ecológico e econômicos desenvolvidos por Martins Júnior (2014) e Martins Júnior e Vasconcelos (2014) podem ser assim resumidos:

a) Zoneamentos ambientais - Método I - (1) os vários geossistemas e modos de expressar suas associações entre rochas, geoformas do relevo, solos e formações superficiais no sentido da Geotecnia, (2) das sub-bacias segundo a sua própria morfometria, (3) do uso dos potenciais ideais da terra para fins agroflorestais e pastoris, (4) da Geotecnia para fins de segurança, mitigação e construções de engenharia, (5) da circulação hídrica, da quantidade e qualidade das águas subterrâneas e superficiais, (6) da vegetação para projetos agrícolas, de silvicultura e pecuária intensiva, e (7) da capacidade assimilativa dos cursos d'água na qual a questão do potencial de depuração natural das águas superficiais ante a poluição se faz importante. Método II - Zoneamentos realizados com objetivos específicos e Método III - Zoneamentos regionais com foco em relevo, solos e vegetação natural.

b) Zoneamentos econômicos em três tipos (1) potencialidades naturais aproveitadas ou não territoriais e climáticas, (2) diagnóstico da atualidade econômica, (3) prospectivo de futuros a serem desenvolvidos.

A partir desses variados tipos de zoneamentos territoriais escolhidos conforme o tema geral da gestão, pode-se partir para o Desenho de Uso Optimal do Território [DUOT] em múltiplos aspectos geoecológicos e econômicos segundo a seleção de resultados dos zoneamentos, cujos objetivos devem ser discutidos, analisados e decididos pelos atores sociais públicos e privados no sentido de se chegar a acordos de futuros com vários cenários possíveis [DUOT- i $(\mathrm{i}=1, \mathrm{n})$ ] a serem perseguidos, tais como políticas de desenvolvimento sustentável ecológica e econômica.

Ao se determinar todos esses cenários possíveis, eles se transformarão em Mapas do Futuro legalmente votados pelo poder legislativo. Esses cenários serão monitorados periodicamente nos tempos predeterminados pelos órgãos públicos e coordenados pelos Comitês de Bacias Hidrográficas (FIG. 2) 


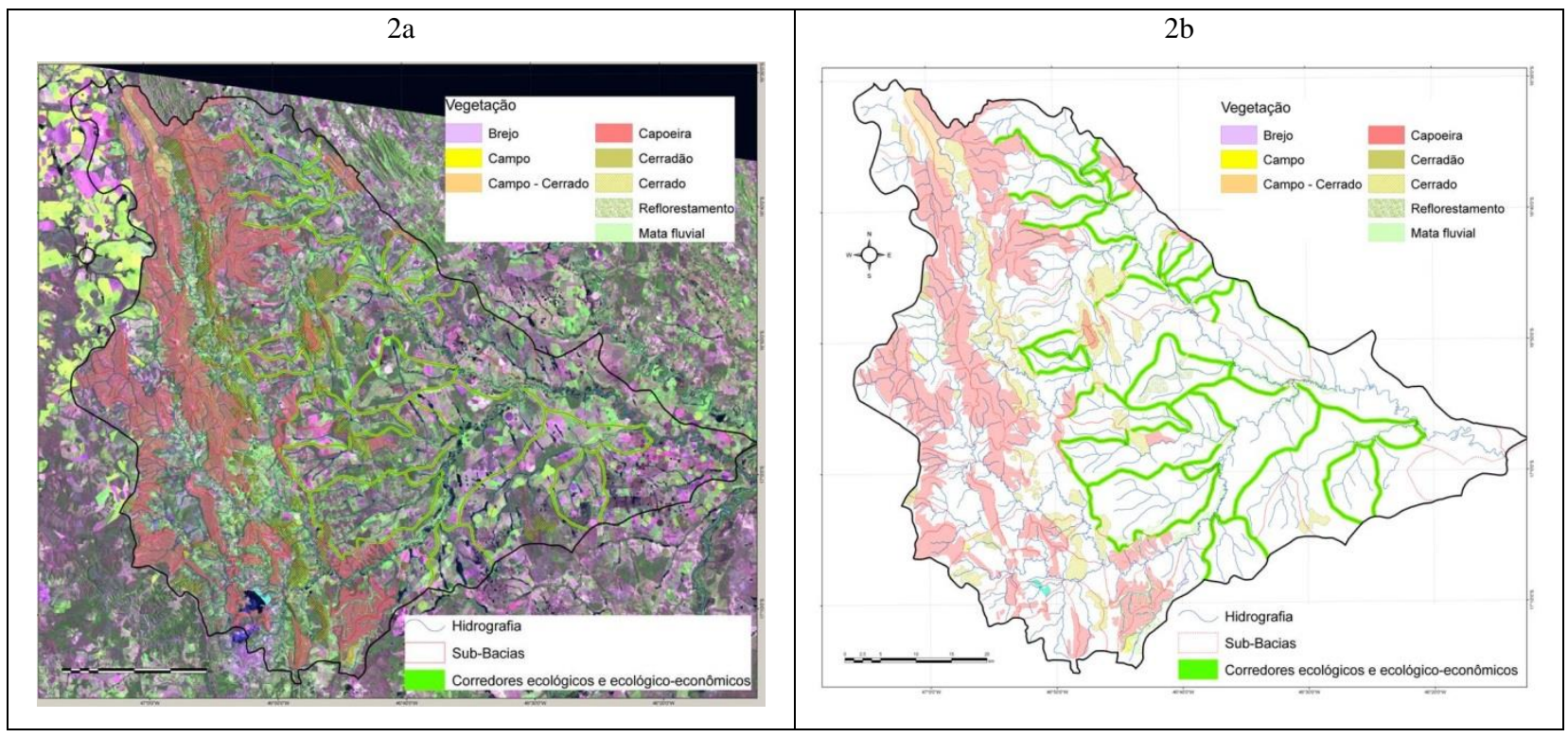

Figuras 2 - 2a: Imagem Landsat da sub-bacia de $3^{\mathrm{a}}$ ordem de Entre Ribeiros no Vale do Paracatu com um cenário de DUOT com corredores ecológicos econômicos entremeados nos campos agrícolas com $1.750 \mathrm{~km}^{2} \mathrm{de}$ agricultura contínua. 2b: Mesmo cenário, mas de modo mais visível.

Fonte: Adaptado de Martins Júnior e Vasconcelos (2014).

\subsection{Bosques e Florestas Plantadas}

O aumento dos bosques de monocultura como, por exemplo, a substituição de áreas campestres pelo plantio de árvores exóticas (PILLAR et al., 2006), em especial o Eucalyptus spp. (SBS, 2008), tem sido cada vez mais disseminada no Brasil, não à toa o país é um dos maiores produtores e consumidores de carvão vegetal do planeta (ABRAF, 2006). Seu objetivo principal é a produção de bioenergia através do carvão vegetal. Assim, perceber esse processo de maneira exclusivamente negativa parece ser um erro, já que:

1) Pode substituir o uso do carvão mineral evitando a reintrodução de $\mathrm{CO}_{2}$ fóssil na atmosfera (PETERS et al., 2017);

2) Aumenta o emprego no campo, mesmo que temporário (OLIVEIRA, 2009);

3) Sua emissão de gás carbônico é menor do que a verificada em queimadas de florestas (BRITO, 1990);

4) Contribui para a conservação dos solos, em especial pela maior intensidade e diversidade de chuva de sementes se comparado a outras áreas (VIEIRA, 2004);

5) Produz carvão vegetal com melhor eficiência possível e, nesse caso, com o uso do forno de tipo "rabo quente" como desenvolvido no CETEC (1988) ou outras formas como fornos de micro-ondas; e 
6) Para a produção de madeira tratada usada tanto na construção civil como na indústria movelaria.

Segundo a proposta aqui sustentada, é notável o fato de que corredores de monocultura possam intercalar-se convenientemente ao plantio de florestas biodiversas, seja em maciços florestais, seja na faixa externa de corredores ecológico-econômicos, seja para recuperação produtiva de área degradada.

Em todo o caso, as florestas monoespecíficas devem obedecer a alguns critérios rigorosos quanto as suas locações no espaço da bacia, a saber:

1) Jamais em áreas que sejam zonas de recarga de aquíferos, pois podem diminuir a recarga, desestabilizando o ciclo hidrológico (REYNOLDS; WOOD, 1977);

2) Em áreas de encostas íngremes, como por exemplo: capim Flexinha (Echinolaena inflexa), Capim Vetiver (Vitiveria Zizanioide) e Camarantuba (Cratylia Argentea) (MARQUES, 2011) em áreas degradadas ou em vias de degradar por ações erosivas;

3) Em áreas já degradadas, pois a liberação de substâncias químicas alelopáticas podem diminuir a fertilidade do solo (JAYAL, 1985); e

4) Como espécies de sustentação financeira para a manutenção das florestas biodiversas plantadas por facilitar regime de manejo e uso de mais alta rotatividade. Exemplos disso são Angico-Vermelho (Anadenanthera macrocarpa), Jacarandá-Branco (Platypodium elegans) e Vinhático (Plathymenia foliolosa), que pelo fato de serem árvores leguminosas, aumentam a fertilidade do solo (CARVALHO; XAVIER; ALVIM, 2003).

Todavia, são condições válidas para todas as florestas plantadas sob a lógica ecológica econômica:

1) Uso adequado de áreas sensíveis ou vulneráveis, desde que sejam usadas espécies arbóreas pioneiras para ocuparem áreas em processo de formação de solo (YARRANTON; MORRISON, 1974);

2) Uso adequado das áreas plantadas, considerando-se os tipos de solos e de condições geoambientais diversas, priorizando-se o plantio do que Ricklefs (1996) denomina de espécies facilitadoras;

3) Espaçamento necessário e adequado, variável de acordo com cada bioma; 
4) Uso dos plantios como medida mitigadora, em especial no caso de espécies arbóreas pioneiras, constatadas por Yarranton e Morrison (1974) como fundamentais para o processo de sucessão primário;

5) Plantio de corredores ecológicos e econômicos prioritariamente com espécies nativas (REIS, 2004); e

6) Balanço de captura de carbono (plantio de florestas mistas apresentam balanço de carbono superior ao chamado plantio puro, segundo Rodrigues, Martins e Leite (2010) com esforço para obtenção de créditos de carbono internacionais, entre outros temas de pertinência.

As bordas de sub-bacias, ou divisores de águas são lugares interessantes e importantes para se plantar verdadeiros corredores com as seguintes condições restritivas:

1) Os corredores terem larguras tais que permitam o crescimento de espécies arbustivas necessárias para constituírem blocos contínuos de plantas. Segundo Camargo (2018), a distância entre cada espécie plantada deve ser cerca de 3m;

2) Permitir o fluxo das diversas espécies nativas de animais pelos corredores, indo de um núcleo florestal a outros núcleos, sobre grandes extensões medidas em centenas de quilômetros, com suficiente isolamento do percurso ou caminho das espécies animais;

3) Permitir o isolamento eventual dos altos das sub-bacias e contribuir direta ou indiretamente para a diminuição efetiva do escoamento superficial bem como favorecer eventuais infiltrações em zonas de recarga aí situadas;

4) Oferecer às espécies animais da região as condições de nutrição próprias de seus hábitos alimentares;

5) Ter espécies de árvores frutíferas, prioritariamente próprias da região; e

6) A faixa central dos corredores ser de plantas nativas.

É de máxima importância realizar-se um programa de longo prazo para assegurar as condições de conservação dos maciços florestais, das fontes com bosques no entorno, e a sobrevivência das espécies animais com as seguintes providências:

1) Eliminação do efeito de borda das matas e maciços florestais remanescentes, considerando-se este efeito como o responsável por isolar trechos de floresta em meio a áreas perturbadas (MURCIA, 1995) e um dos mais graves problemas presentes na fronteira agrícola do Brasil central (VIANA; TABANEZ; MARTINEZ, 1992); 
2) Impedir a distribuição de animais criados em cativeiro nessas áreas de preservação;

3) Implantação dos corredores com estruturas adequadas para longas distâncias interligando maciços florestais, a exemplo do realizado por Camargo (2018); e

4) Criação de hortos altamente especializados em plantio de espécies nativas e de espécies ecológico-econômicas para futuro replantio nestes corredores.

Entre as condições de planejamento do plantio estão as condições de localização preferencial das diversas espécies em face do manejo, o que significa a adequação das coletas, derrubadas, arrastos e replantio. As florestas ecológicas e econômicas, tanto na forma de maciços, quanto de corredores plantados, podem agir como medidas mitigadoras em áreas erodíveis e erodidas, contribuindo na contenção e conservação de solos e rochas, como mostrou Teixeira, Camargo e Martins Junior (2018) em estudos no cerrado presente no Norte de Minas Gerais.

\section{CONCLUSÕES}

Os modelos aqui discutidos integram uma visão de viabilidade ecológica e econômica entre plantios florestais ecológicos e econômicos, com preservação do bioma, conservação da circulação hídrica e uso da agricultura intensiva para a produção de biomassa geradora de energia. Além disso, apresentam o adequado plantio e manejo de madeiras de lei, frutos e insumos agrícolas com foco na sustentabilidade das bacias hidrográficas.

Trata-se, assim, de um artigo capaz de debater modelos lógicos que, a todo tempo, devem ser negociados entre os vários atores sociais como modo de buscar soluções efetivas para as variadas formas de conflitos ambientais capazes de causar degradação do uso do solo. Assim, enxerga-se esse trabalho como um macro modelo teórico capaz de contribuir epistemologicamente para a recuperação de terras amplamente desmatadas e já abandonadas, permitindo a reintrodução das mesmas nos ciclos naturais e econômicos, mesmo que de modo progressivo.

\section{REFERÊNCIAS}

AB'SABER, A. N. Os domínios de natureza no Brasil: potencialidades paisagísticas. São Paulo: Ateliê Editorial, 2003. 160 p. 
ADGER, W. N. Social and ecological resilience: are they related? Progress in Human Geography, v. 24, n. 3, p. 347-364, 2000.

ASSOCIAÇÃO BRASILEIRA DE PRODUTORES DE FLORESTAS (ABRAF). Anuário estatístico da ABRAF: ano base 2005. Brasília: ABRAF, 2006. Disponível em: http://www.abraflor.org.br/estatisticas.asp. Acesso em: jun. 2018.

BERGER, R. Crescimento e qualidade da madeira de um clone de Eucalyptus saligna Smith sob o efeito do espaçamento e da fertilização. 2000. 126 f. Dissertação (Mestrado em Engenharia Florestal) - Universidade Federal de Santa Maria, Santa Maria, 2000.

BOMBARDI, L. M. Geografia do uso de agrotóxicos no Brasil e conexões com a União Europeia. São Paulo: Laboratório de Geografia Agrária, 2017. 296 p.

BRASIL. Balanço energético nacional 2003. Brasília: Ministério das Minas e Energia, 2003. $154 \mathrm{p}$.

BRITO, J. O. Princípios de produção e utilização do carvão vegetal de madeira. Piracicaba: ESALQ, 1990. 19 p. (Documentos Florestais, 9).

CAMARGO, P. L. T. Soluções biogeográficas de geoconservação com ênfase nas relações entre solo, água e planta na bacia do Rio Pardo e suas adjacências, São Francisco, norte de Minas Gerais. 2018. 404 f. Tese (Doutorado em Evolução Crustal e Recursos Naturais) Escola de Minas, Universidade Federal de Ouro Preto, Ouro Preto, 2018.

CAMARGO, P. L. T et al. Áreas degradadas e corredores ecológicos: algumas propostas metodológicas de plantio e manejo para conservação ambiental. In: FÓRUM BRASIL DE ÁREAS DEGRADADAS, 4., 2017, Viçosa. Anais... Viçosa: UFV, 2017. p. 32-35.

CARVALHO, M. M.; XAVIER, D. F.; ALVIM, M. J. Arborização melhora a fertilidade do solo em pastagens cultivadas. Juiz de Fora: Embrapa Gado de Leite, 2003. 4 p. (Embrapa Gado de Leite. Comunicado Técnico 29).

ELLIOT, L. The global politics of the environment. Londres: Macmillan, 1998.

FUNDAÇÃO CENTRO TECNOLÓGICO DE MINAS GERAIS (CETEC). Manual de construção e operação do forno rabo quente. Belo Horizonte: CETEC, 1988. 62 p.

HOLLING, C. S. Surprise for science, resilience for ecosystems, and incentives for people. Ecological Applications, v. 6, n. 3, p. 733-735, 1996.

JAYAL, N. D. Destruction of water resources: the most critical ecological crisis of East Asia. Ambio, v. 14, n. 2, p. 95-98, 1985.

KLUBNIKIN, K.; CAUSEY, D. Environmental security: metaphor for the millenium. Seron Hall Journal for Diplomacy and International Relations, v. 3, n. 2, p. 104-133, 2002.

LORENZI, H. Árvores brasileiras: manual de identificação e cultivo de plantas arbóreas nativas do Brasil. Nova Odessa: Plantarum, 1997, 352 p. 
MARQUES, T. E. D. Uso de gramíneas em consórcio com leguminosas para recuperação de voçorocas. 2011. 83 f. Dissertação (Mestrado em Ecologia de Biomas Tropicais) Instituto de Ciências Exatas e Biológicas, Universidade Federal de Ouro Preto, Ouro Preto, 2011.

MARTINS JUNIOR, P. P. Epistemologia fundamental: um estudo introdutório sobre a estrutura do conhecimento e a aplicação prática da epistemologia na pesquisa científica. Ouro Preto: UFOP, 2014. 272 p. Apostila.

MARTINS JUNIOR, P. P. Fundamentos conceituais para o desenvolvimento e a prática das geociências agrárias e ambientais. A Terra em Revista, n. 4, p. 10-15, 1998.

MARTINS JUNIOR, P. P. et al. Environmental impact assessment of natural and anthropologically induced erosion process in 4th degree codornas drainage basin. In: INTERNATIONAL SYMPOSIUM ON ENVIRONMENTAL GEOTECHNOLOGY AND GLOBAL SUSTAINABLE DEVELOPMENT, 4., 1998, Boston. Anais... Boston, 1998. p. 912.

MARTINS JUNIOR, P. P. et al Arquitetura de conhecimentos em ecologia-economia para gestão ambiental de bacia hidrográfica. Belo Horizonte: Fundação CETEC, 2008. 237 p. (Relatório do Projeto ACEE 2005-2008).

MARTINS JUNIOR, P. P. et al Modelo de integração de conhecimentos geológicos para auxílio à decisão sobre uso da terra em zonas de recarga de aquíferos. Revista Brasileira de Geociências, v. 36, n. 4, p. 651-662, 2006.

MARTINS JUNIOR, P. P. et al. Lógica para modelos de integração de conhecimentos para auxílio à decisão: plantios florestais ecológico-econômicos em zonas de recarga de aquíferos. Revista Brasileira de Geociências, v. 40, n. 1, p. 80-98, 2010.

MARTINS JUNIOR, P. P.; VASCONCELOS, V. V. Gestão de bacia hidrográfica: instrumentos o quê e para quê. Ouro Preto: UFOP, 2014. 288 p. Apostila.

MARTINS JUNIOR, P. P. et al. Modelagem geo-ambiental e interdisciplinar para ordenamento do território com corredores florestais ecológico-econômicos. Revista de Geologia, v. 21, n. 1, p. 79-97, 2008.

MURCIA, C. Edge effects in fragmented forests: implications for conservation. Trends in Ecology \& Evolution, Oxford, v. 10, n. 2, p. 58-62, 1995.

OLIVEIRA, A. M. S. Reordenamento territorial e produtivo do agronegócio canavieiro no Brasil e os desdobramentos para o trabalho. 2009. 566f. Tese (Doutorado em Geografia) -Universidade Estadual Paulista, Presidente Prudente, 2009.

OLIVEIRA, I. S. D. A contribuição do zoneamento ecológico econômico na avaliação do impacto ambiental: bases, propostas conceituais. 2004. 111 f. Dissertação (Mestrado em Ciências da Engenharia Ambiental) - Escola de Engenharia de São Carlos, Universidade de São Paulo, 2004.

PETERS, S. R. et al. Simulação da cogaseificação de carvão mineral e casca de arroz para a produção de hidrogênio. In: CONGRESSO BRASILEIRO DE CARVÃO MINERAL, 5., 
2017, Criciúma. Anais eletrônicos... Criciúma, 2017. [p. 1-6]. Disponível em http://www.swge.inf.br/ANAIS/CBCM2017/PDF/CBCM2017-0120.PDF. Acesso em: 12 jun. 2018.

PILLAR, V. P. et al. Workshop "Estado atual e desafios para a conservação dos campos". Porto Alegre: Universidade Federal do Rio Grande do Sul, 2006. 24 p. Disponível em: http://www.ecologia.ufrgs.br/ecologia/workshop_campos\%20RS2006.pdf. Acesso em: 9 jun. 2018.

REIS, A. Restauração de áreas degradadas: imitando a natureza. Florianópolis: Universidade Federal de Santa Catarina, 2004. 73 p.

REYNOLDS, E. R. C.; WOOD, P. J. Natural versus man-made forests as buffer against environment deterioration. Forest Ecology and Management, v. 1, p. 83-96, 1977.

REZENDE, J. L. P.; PEREIRA, A. R.; OLIVEIRA, D. Espaçamento ótimo para produção de madeira. Revista Árvore, v. 7, n. 1, p. 30-43, 1983.

RODRIGUES, B. D.; MARTINS, S. V.; LEITE, H. G. Avaliação do potencial da transposição da serapilheira e do banco de sementes do solo para restauração florestal em áreas degradadas. Revista Árvore, Viçosa, v. 34, n. 1, p. 65-73, 2010.

RICKLEFS, R. E. A economia da natureza. Rio de Janeiro: Guanabara Koogan, 1996. 503 p.

ROSA, R. Introdução ao sensoriamento remoto. 6. ed. Uberlândia: EDUFU, 2007. 248 p.

SOCIEDADE BRASILEIRA DE SILVICULTURA (SBS). Fatos e números do Brasil florestal. São Paulo: SBS, 2008. Disponível em: http://www.sbs.org.br/FatoseNumerosdoBrasilFlorestal.pdf. Acesso em: jun. de 2018.

SHIMOYAMA, V. R. S.; BARRICHELO, L. E. G. Densidade básica da madeira, melhoramento e manejo florestal. Série Técnica IPEF, v. 6, n. 20, p. 1-22, 1989.

TEIXEIRA, M. B. Implicações geoambientais para o desenvolvimento da teoria do sistema computacional de suporte à decisão para gestão do território e da erosão dos solos. 2018. 360 f. Tese (Doutorado em Evolução Crustal e Recursos Naturais) - Escola de Minas, Universidade Federal de Ouro Preto, Ouro Preto, 2018.

TEIXEIRA, M. B.; CAMARGO, P. L. T.; MARTINS JUNIOR, P. P. Uso das Imagens de Sensores Remotos para Análise Crítica da Degradação do Cerrado no Alto Médio São Francisco. Minas Gerais. Anuário do Instituto de Geociências (UFRJ Impresso), Rio de Janeiro, v. 41, p. 245-254, 2018.

VIANA, V. M.; TABANEZ, A. A. J.; MARTINEZ, J. L. A. Restauração e manejo de fragmentos florestais. Revista do Instituto Florestal, São Paulo, v. 4, parte 2, p. 400-407, 1992.

VIEIRA, N. K.. O papel do banco de sementes na restauração de restinga sob talhão de Pinus elliottii Engelm. 2004. Dissertação (Mestrado em Biologia Vegetal) - Centro de Ciências Biológicas, Universidade Federal de Santa Catarina, Florianópolis, 2004. 
VICENTE, J. R. Pesquisa, adoção de tecnologia e eficiência na produção agrícola. São Paulo: Apta/SAAESP, 2002. 153 p.

YARRANTON, G. A.; MORRISON, R. G. Spatial dynamics of a primary succession: nucleation. Journal of Ecology, Oxford, v. 62, n. 2, p. 417-428, 1974.

\section{DADOS DOS AUTORES}

\section{Pedro Luiz Teixeira de Camargo}

Currículo Lattes: http://lattes.cnpq.br/4123026034662869

E-mail: pedro.camargo@ifmg.edu.br

Doutor em Ciências Naturais e mestre em Sustentabilidade Socioeconômica e Ambiental pela UFOP-MG. Especialista em Gestão Ambiental e em Planejamento e Gestão da Educação a Distância (UFF-RJ). Possui ainda Graduação em Geografia (Faculdades Integradas de Ariquemes - FIAR) e em Ciências Biológicas (UFOP-MG). Atualmente é Professor efetivo de Ciências Biológicas (Técnico Integrado), Introdução à Engenharia Ambiental, Economia Ecológica e Ambiental e Recuperação de Áreas Degradas (Engenharia Civil) do IFMG Campus Piumhi.

\section{Paulo Pereira Martins Junior}

Currículo Lattes: http://lattes.cnpq.br/1323327733767945

E-mail: paulomartins@epamig.br

Graduado em Geologia pelo Instituto de Geociências da Universidade Federal do Rio de Janeiro (1970) e doutorado pela Université Pierre et Marie Curie Paris VI, Laboratoire de Géologie Dynamique - Docteur en Science de La Terre (Dr.Sc.T.) em 1977. Atuo como Professor Associado IV no Departamento de Geologia, Escola de Minas, Universidade Federal do Ouro Preto. Sou professor no programa de Evolução Crustal e Recursos Naturais, área de concentração Geologia Ambiental e Conservação de Recursos Naturais. Também ensino na Rede de Ciência dos Materiais REDEMAT (UFOP - UEMG) no mestrado e doutorado, assim como no mestrado em Sustentabilidade Sócio Ambiental e Econômica da Escola de Minas. 